\title{
RADIOGRAPHIC EVALUATION OF THE EFFECT OF DIFFERENT MINI-IMPLANTS DISTRIBUTION ON POSTERIOR MANDIBULAR RIDGE HIGHT IN MANDIBULAR MINI-IMPLANTS ASSISTED OVERDENTURES CASES. AN 6-YEAR RETROSPECTIVE STUDY
}

\author{
Kawkb Mohmad Tamimi* and Ahmad Mohmad Elrawdy**
}

\begin{abstract}
Statement of problem: Mandibular overdentures assisted by mini-implants induce sever bone changes in posterior mandible.

Purpose: This study aimed to evaluate the posterior mandibular ridges height changes using the digital panoramic radiographic technique under mandibular overdentures assisted by four mini-implants, in case of interforaminal distribution and in case of wide distribution after wearing overdentures for 6 years.
\end{abstract}

Methods and material: The subjects enrolled for this study $(n=20)$. They were treated with maxillary complete dentures, randomly assigned into two equal groups: Group (I) received mandibular overdent ures assisted by four mini-implants distributed equally in the interforaminal region, exposed to immediate loading protocol. Group (II) received mandibular overdentures assisted by four mini-implants (two mini-implants inserted in canine regions and two miniimplants inserted in first molar regions) exposed to immediate loading protocol. Digital panoramic radiographic evaluation of posterior mandibular region was done for every patient of both groups, recorded at the time of mini-implants insertion and after 6 years.

Results: There was statistically significant difference in bone heights changes between interforaminal and wide distribution groups after six years. There was bone apposition in the wide distribution at $15 \mathrm{~mm}$ and $20 \mathrm{~mm}$ distal to mental foramen.

Conclusion: Posterior mini implants placement resulted in improved denture support and minimal overdenture displacement. The functional load on posterior mini implants has a positive effect on preservation of the residual alveolar ridge. Wide mini implants distribution is an acceptable alternative prosthodontic design to four-interforaminal mini implants distribution when anatomical and economical factors permit.

Keywords: Mini-implants distributions, mini-implants assisted overdenture, posterior mandibular ridge height changes, wide distribution, interforaminal distribution, digital panoramic radiographic evaluation.

* Depatrtment of Prosthodontics, Faculty of Dentistry, Suez Canal University.

** Assistant Professor, Oral Radiology Department, Faculty of Dentistry. Suez Canal University 


\section{INTRODUCTION}

Complete dentures posse multiple deficiencies such as insuffient retention, stability and decreased chewing efficiency (1). These drawbacks are aggravated by residual ridge resorption due to overall remodeling following teeth extraction and denture use ${ }^{(2)}$. An implant-stabilized overdenture is treatment modality that removes many of the complete dentures problems and gets better function and comfort for edentulous patients. ${ }^{(3)}$ The presence of implants to stabilize an overdenture will preserve the remaining bony ridge ${ }^{(4)}$.

The mini implants are $3 \mathrm{~mm}$ in diameter. ${ }^{(5)}$ Miniimplants may be the best choice of treatment for patients with inadequate ridge width, which does not allow the placement of conventional sized implants without further surgical procedures ${ }^{(6-9)}$. Four mini-implants at the interforaminal region have been exposed for immediate loading with mandibular overdentures $(6,8,10,11)$. These miniimplants were able to improve the mandibular overdenture's retention, the patient's life quality, the patient's satisfaction, and the chewing ability of the overdenture wearers ${ }^{(6,8)}$.

This improvement in oral functions and bite force in two or four implants assisted overdentures may cause more stress concentration that does not exist in conventional denture ${ }^{(1)}$. Due to the fixation of the overdenture anteriorly in the interforminal area, the axial direction of force and the free movement posteriorly may induce more resorption posteriorly than anteriorly ${ }^{(12,13)}$.

Studies recommended the interforaminal implant overdenture as a suitable way of treatment of edentulous mandible without considering for posterior bone resorption ${ }^{(14)}$.

Jacobs et $\boldsymbol{a l}^{(12)}$ found more posterior mandibular ridge resorption in implant retained overdenture cases than complete denture cases over the same period. Marjolein et al ${ }^{(1)}$ reported a significant difference in posterior ridge resorption between two and four implants assisted overdenture. For two implants, assisted overdenture the vertical posterior bone loss was $1.44 \mathrm{~mm}$ in 10 years. For four implants assisted overdenture the vertical posterior bone loss was $0.74 \mathrm{~mm}$ over the same period.

Wright et al ${ }^{(15)}$ found that patients treated with implant-stabilized mandibular overdentures showed low rates of posterior mandibular residual ridge resorption, of $0.5 \mathrm{~mm}$ over 5 years whereas Kordatzis et al ${ }^{(16)}$ reported 0.69 to $1 \mathrm{~mm}$ of posterior residual ridge resorption over the same period. Raedel et $\boldsymbol{a l}^{(14)}$ found posterior bone resorption of two implants bar retained overdentures was $1.5 \mathrm{~mm}$ in 10 years.

Panoramic radiography is commonly used in large institutional practices as good method of screening edentulous and dentate patients ${ }^{(17)}$.

The panoramic radiographs of the jaws is part of the preprosthetic examination provide a graphic picture of bone resorption, especially in the mandible. In films of edentulous mandible, the superior and inferior borders of the mandible and the mental foramen are the only remaining radiographic landmarks in the body of the mandible. The present research used the image of the mental foramen as a reference point for assessment of the amount of alveolar bone resorption ${ }^{(18)}$.

We pose the following question because of this situation: is the wide distribution of mini-implants in mandibular arch improves posterior ridge resorption.

\section{MATERIALS AND METHODS}

\section{Sample size calculation}

The sample size for this study was calculated according to Arkin ${ }^{(19)}$ and Jaykaran and Tamghna ${ }^{(20)}$ used the following equation:

$$
\begin{aligned}
& \mathbf{N}=\frac{(\mathrm{Z} \alpha)^{2} \times(\mathrm{SD})^{2}}{(\mathrm{D})^{2}} \\
& \mathbf{N}=\text { Total sample size }
\end{aligned}
$$


$\mathbf{Z} \boldsymbol{\alpha}=$ Is Standard normal variate and its equal 1.96 at $\mathrm{P}<0.05$

$$
\begin{aligned}
& \mathrm{SD}=\text { Standard diversion of variable } \\
& \mathrm{d}=\text { Absolute error or precision }
\end{aligned}
$$

\begin{tabular}{|c|c|c|}
\hline $\mathrm{Z} \alpha$ & SD & d \\
\hline 1.96 & 4.55 & 2 \\
\hline
\end{tabular}

Total Sample size $\mathrm{N}=\frac{(1.96)^{2} \times(4.55)^{2}}{(2)^{2}}=19.883$ $\approx 20$ samples

$(2)^{2}$

Twenty male patients had completely edentulous ridges selected from the outpatients clinic, faculty of dentistry, suez canal University. The study protocol was explained in details to all patients and their consents for participating in the study were taken.

\section{Patient selection}

The selected patients had the following criteria: Free from any systemic diseases detected by blood / urine analysis that may affect bone quality and quantity. Their ages ranged from 50 to 60 years old with adequate inter-arch space, had a good oral hygiene, angle's Class I jaw relationship with adequate height of the residual ridges, no bad habits including heavy smoking, bruxism, clenching or tongue thrusting.

\section{Dentures insertion}

Upper and lower acrylic complete dentures were delivered to all patients with lingualized occlusal scheme with anterior light contact. The patients were recalled for necessary adjustments.

\section{Patients grouping}

The patients were divided into two equal groups according to mini-implants distribution.

Group I: The patients received four miniimplants distributed equally in the interforaminal region and exposed to immediate loading protocol.

Group II: The patients received four miniimplants, one mini-implant installed in the canine region, and one mini-implant installed in the first molar region in each side of the arch and exposed to immediate loading protocol.

\section{Mini-implants insertion}

The finished lower denture duplicated for each patient and processed in transparent acrylic resin radiographic stent. At the proposed site for each mini-implant, holes were drilled through the fitting surface of the stent to accommodate a stainless-steel ball ( $2 \mathrm{~mm}$ diameter). The balls were totally submerged into the holes. Panoramic radiograph was made with the radiographic stent in the patient's mouth. The ball's images were used to assess the bone height at the proposed mini-implant sites. According to the flapless surgical technique with atraumatic osteotomy and adjustable torque ratchet, four mini-implants (Dentium Co., Korea) $2.5 \mathrm{~mm}$ in diameter and 10 or $12 \mathrm{~mm}$ in length were used according to bone height. The mini-implant sites in group I were four mini-implants distributed equally in the interforminal area. A minimum of $5 \mathrm{~mm}$ mesio-distal distance was kept between adjacent mini-implants in group (I). The mini-implants sites in group (II) were two mini-implants in cusped area and another two mini-implants in the first molar area in each side of the mandible. The mini-implants were installed by using the single-stage flapless surgical approach.

\section{Direct Pick-up Procedure}

As soon as the four mini-implants installed, undercut areas around the mini-implant heads were covered using sterile orthodontic O-rings. The female metallic housing caps were placed on the miniimplants. The female house surface marked with marker; the lower denture seated in patient's mouth. The areas opposing the housings were marked on the tissue surface of the denture. The marked areas were removed, until a clearance space of about $1-2 \mathrm{~mm}$. was provided around the metallic housings. The maxillary and mandibular dentures were seated into the patient's mouth to verify the complete seating of the lower denture without any interferences, 
rocking or occlusal discrepancy. Four holes were then created in the lingual flange below the artificial teeth to allow the escapement of excess material.

A special type of self-cured acrylic resin that does not generate heat (Secure Hard Pick-Up Kit, 3M ESPE, USA) was mixed and applied in the dough stage to the relieved areas of the fitting surface of the denture. The mandibular denture was reseated in the patient's mouth. The patient was instructed to close in centric occlusion. After complete polymerization, the denture was removed from the patient's mouth picking up the metal housings. Excess material was trimmed using finishing stone, the mandibular miniimplants assisted over-denture was repolished and delivered to the patient, and the denture was placed in immediate functional loading on the same day of mini-implants placement.

\section{Radiographic evaluation}

\section{Bone height measurements (Linear analysis)}

The patients were subjected to two consecutive Direct digital panoramic radiographs, initial record after completing implants insertion (T0), and the final record after 6-years post-insertion (T6) respectively. The panoramic images were performed using digital panoramic machine (Sirona, ORTHOPHOS XG5 Ds/ Ceph., Germany) with CCD sensor technology and $27 \mu \mathrm{m}$ pixel size. The exposure parameters for all patients was $64 \mathrm{KVp}, 8 \mathrm{Ma}$, and $14.1 \mathrm{sec}$ exposure time. All images were captured, analyzed processed and stored using SIDEXIS XG software (SIDEXIS
XG image processing software, Sirona Dental System, Germany).

The patients were positioned according to the standard procedure described by Stuart and Michael ${ }^{(21)}$, as follows:

- The patient head was carefully aligned in the focal trough so the both arches are located in the middle of the focal trough.

- We removed the bite block, instead we placed the metal bar in such case the arch facing toward the column.

- The upper and lower arches are in line by using cotton pellet between them.

- The midsagittal plane was adjusted within the exact of focal trough and perpendicular to the floor.

- The Frankfort plane was aligned parallel with the floor.

- The patient's back and spine was adjusted to be erect with extended neck position.

For standardized measurements, reference lines were traced as perpendiculars from the lower border of the mandible (LBM) to the ridge crest (RC). Four regions on right and left side were identified; first region was at the tangent line to the posterior border of the mental foramen, second, third and fourth region were consecutively located $5 \mathrm{~mm}$ further distally fig (1) and fig. (2).

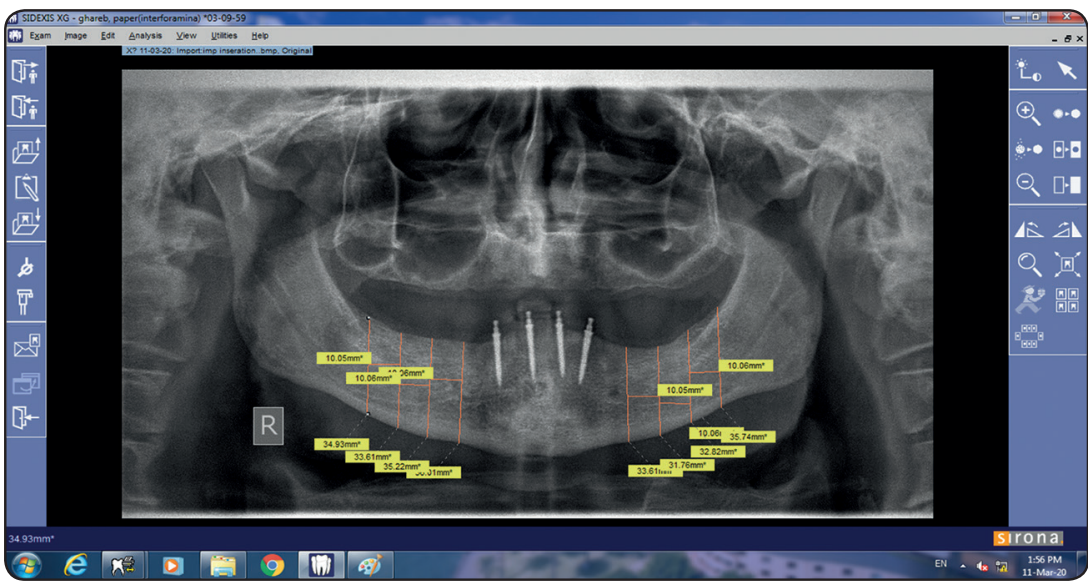

Fig. (1): Digital panoramic radiograph for interforaminal group, bone height measurements (Linear analysis), distal mental foramen. 


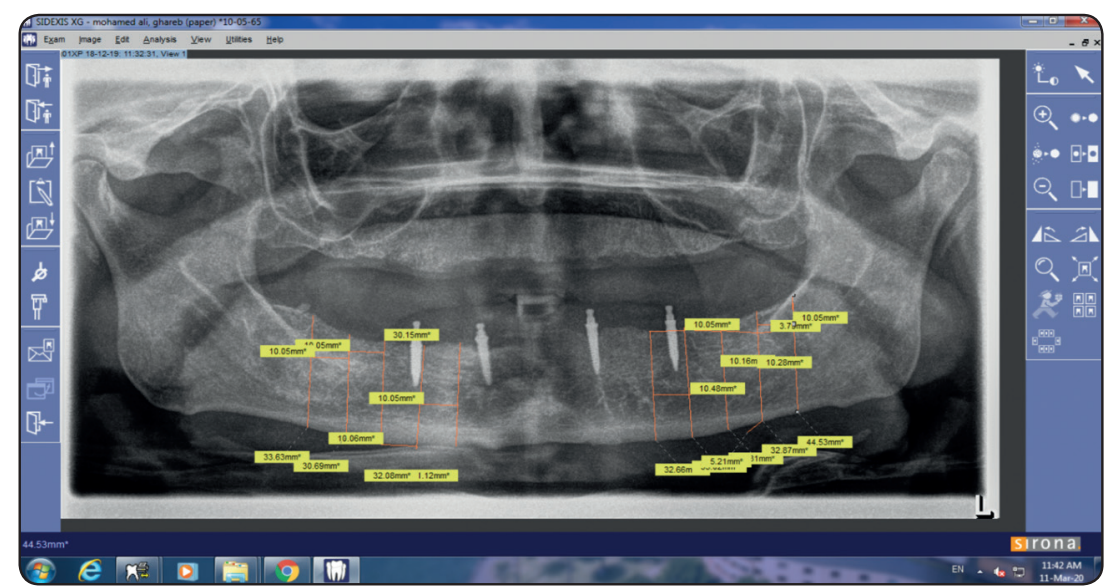

Fig. (2): Digital panoramic radiograph for wide distribution group bone height measurements (Linear analysis), distal mental foramen.

A vertical line (VL) was drawn from the most upper point of (RC) to the most inferior point of the lower border of the mandible (LBM) through the long axis of the bone segment. The height of the alveolar bone $(\mathrm{H})$ was defined as the distance from $\mathrm{RC}$ to LBM.

The linear vertical resorption of the mandibular residual alveolar ridge was determined as the difference in height of the alveolar process during the two stages of observation.

The bone measurements were done by the same radiologist using the same technique, and were repeated twice with an interval of 2 weeks to evaluate the reproducibility of the measurements, and the precision was calculated (the coefficient of variation to confirms the examiner's measurements a high exactness).

Calculated differences in the alveolar ridge dimensions at $\mathrm{T} 6$ from $\mathrm{T} 0$ were expressed in tenth of millimeters. Positive values indicated resorption, and negative values indicated the bone apposition.

\section{Statistical analysis}

All data was calculated, tabulated and statistically analyzed using suitable statistical tests as follow. A normality test was done to check normal distribution of the sample, and all groups. Statistical analysis was performed using the computer program SPSS software for windows version 22.0 (Statistical
Package for Social Science, Armonk, NY: IBM Corp) at significant levels 0.05 (P-Value $\leq 0.5$ ).

\section{a) Descriptive data:}

Descriptive statistics will be calculated in the form of Mean \pm Standard deviation (SD), range (Max-Min), median, Coefficient of variance (C.V\%) .....etc.

\section{b) T-test}

Dependent and independent T-test, were performed for comparison of the mean differences between the two groups at the same time

\section{RESULTS}

\section{Descriptive statistics:}

Descriptive statistics of residual ridge measurements in interforaminal group for both sides are presented in table (1).

From table (1) there was significant difference in bone heights changes after six years in interforaminal distribution group. Positive values indicate bone resorption. Figure (3) shows that there was significant decrease in bone height after six years at 5, 10, 15 and $20 \mathrm{~mm}$.

Descriptive statistics of residual ridge measurements in wide distribution group for both sides are presented in table (2). 
Positive values indicate bone resorption, negative values indicate an increase in the heights of posterior residual ridge or bone apposition.

From table (2) there was no significant difference in bone heights changes after six years in wide distribution group. Figure (4) shows that at 5 and $10 \mathrm{~mm}$ there were minute bone loss but at 15 and 20 $\mathrm{mm}$ there were bone apposition.
Comparisons: Table (3) figure (5) shows the results of comparisons between the bone height changes for interforaminal and wide distribution groups in both right and left sides.

From table (3) and figure (5) there was significant difference in bone heights changes between interforaminal and wide distribution groups after six years. There is bone apposition in the wide distribution at $15 \mathrm{~mm}$ and $20 \mathrm{~mm}$.

TABLE: (1) Comparison between the mean bone height changes every $5 \mathrm{~mm}$ distal to mental foramen of mandibular alveolar ridge in interforaminal distribution group.

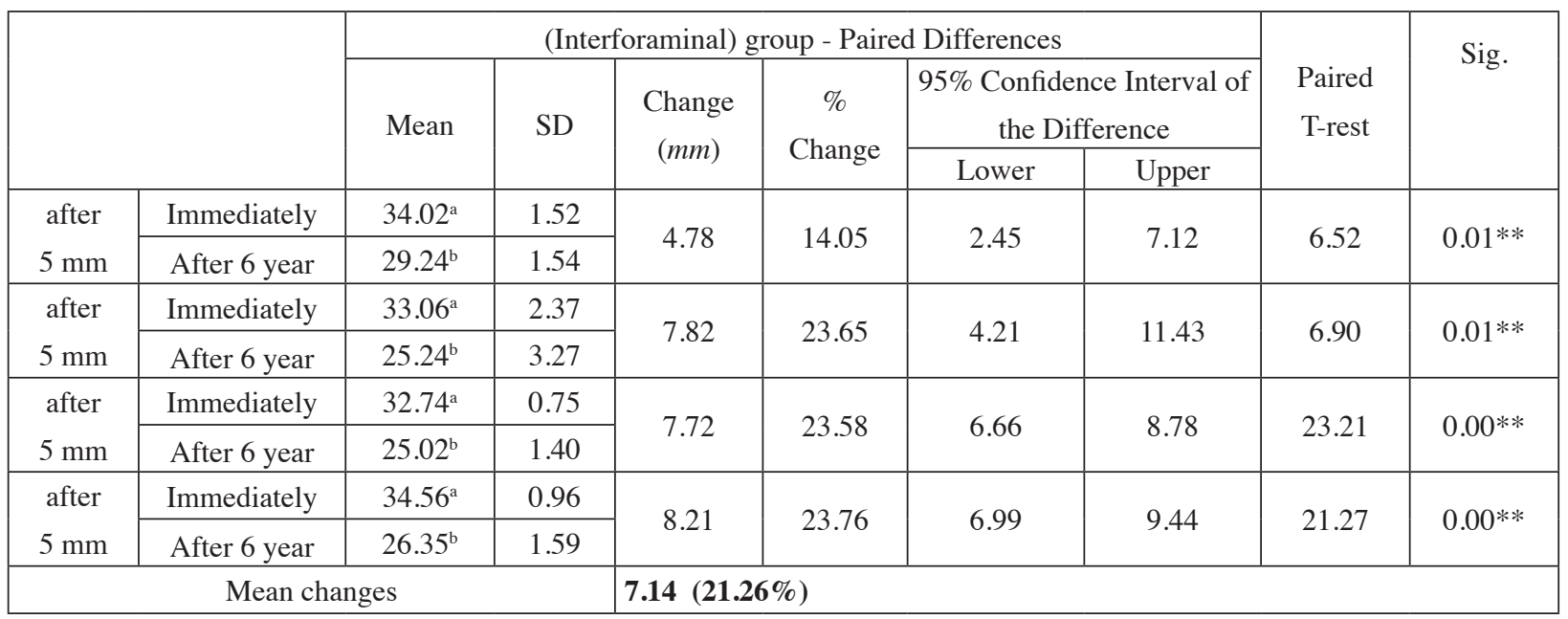

${ }^{* *} ;{ }^{a b}$ means significant difference between groups at $P$ value $<0.05$

TABLE (2) Comparison between the mean bone height changes every $5 \mathrm{~mm}$ distal to mental foramen of mandibular alveolar ridge in wide distribution group.

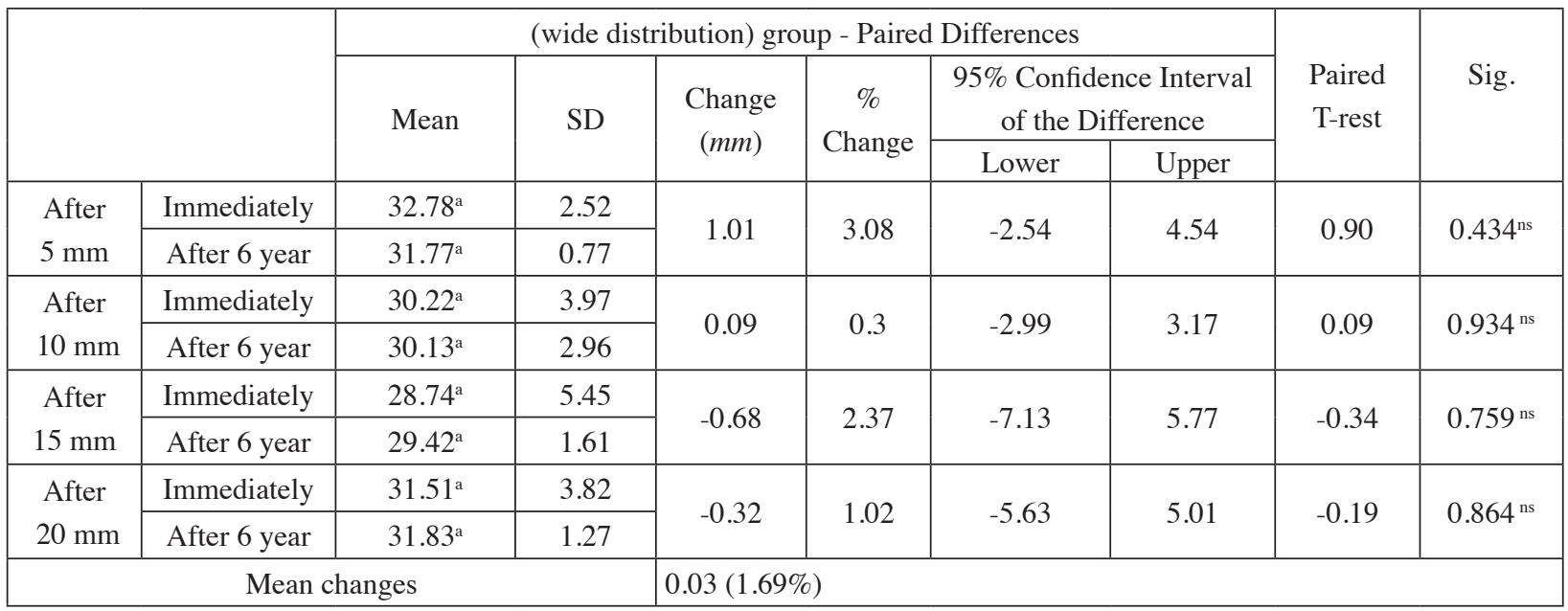




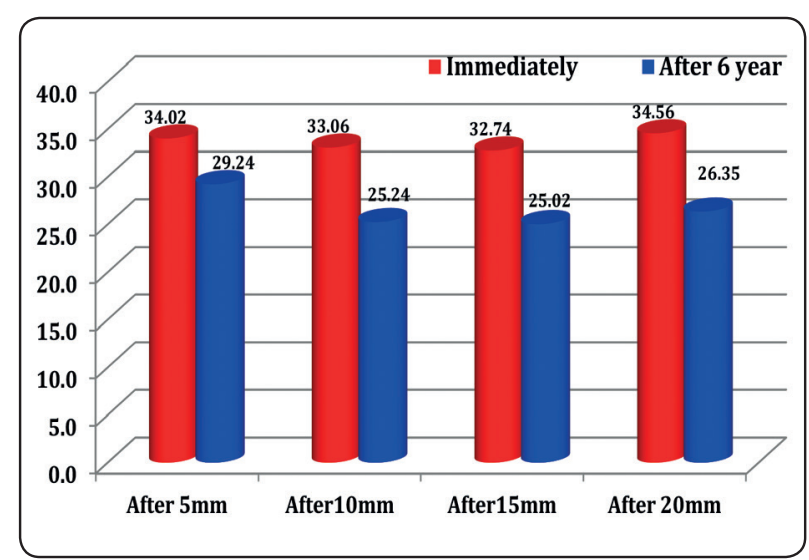

Fig. (3) Showing bone heights changes in interforaminal distribution group

TABLE (3) Comparison between the mean bone height changes every $5 \mathrm{~mm}$ distal to mental foramen of mandibular alveolar ridge in both groups.

\begin{tabular}{|c|c|c|c|c|}
\hline & $\begin{array}{c}\text { wide } \\
\text { distribution }\end{array}$ & $\begin{array}{c}\text { Inter- } \\
\text { foraminal }\end{array}$ & \multirow{2}{*}{$\begin{array}{c}\text { Independent } \\
\mathrm{T} \text {-Test }\end{array}$} & \multirow{2}{*}{$\begin{array}{c}\text { p-values } \\
<0.05\end{array}$} \\
\hline & Mean \pm SD & Mean \pm SD & & \\
\hline After $5 \mathrm{~mm}$ & $1.00 \pm 2.23^{\mathrm{b}}$ & $4.78 \pm 1.47^{\mathrm{a}}$ & -2.84 & $0.030 * *$ \\
\hline After $10 \mathrm{~mm}$ & $0.09 \pm 1.94^{\mathrm{b}}$ & $7.82 \pm 2.27^{\mathrm{a}}$ & -5.18 & $0.002 * *$ \\
\hline After $15 \mathrm{~mm}$ & $-0.68 \pm 4.05^{b}$ & $7.72 \pm 0.67^{\mathrm{a}}$ & -4.16 & $0.006 * *$ \\
\hline After $20 \mathrm{~mm}$ & $-0.31 \pm 3.34^{b}$ & $8.22 \pm 0.77^{\mathrm{a}}$ & -4.97 & $0.003 * *$ \\
\hline
\end{tabular}

**; ${ }^{a b}$ means significant difference between groups at $P$ value $<0.05$

\section{DISCUSSION}

Since the use of implant installed in the posterior part of the mandible and their effect on stress distribution was point of concern in late years the present study aimed to assess the effect of miniimplants distribution on posterior residual alveolar ridge. Either the mini-implants assisted overdenture assisted by four mini implants installed in the interforaminal area or four mini-implants installed in the canine and first molar area in mandibular mini-implants assisted overdenture opposed by maxillary complete denture.

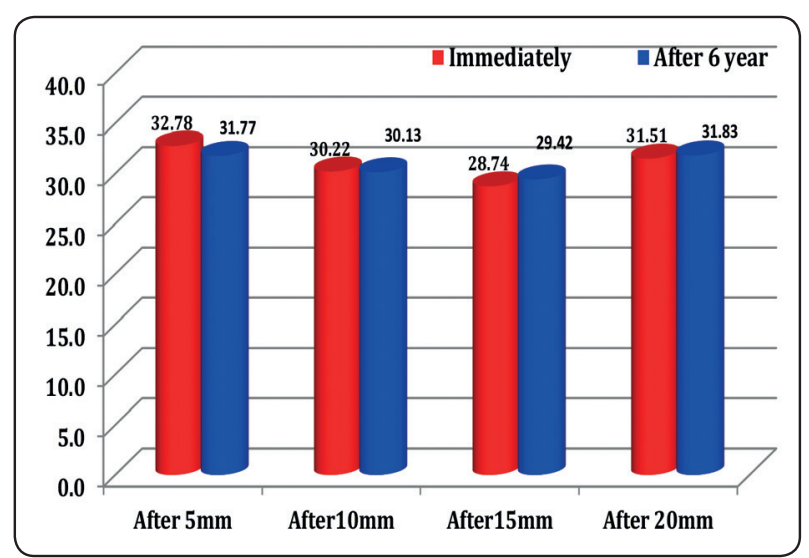

Fig. (4) Bone heights changes in wide distribution group

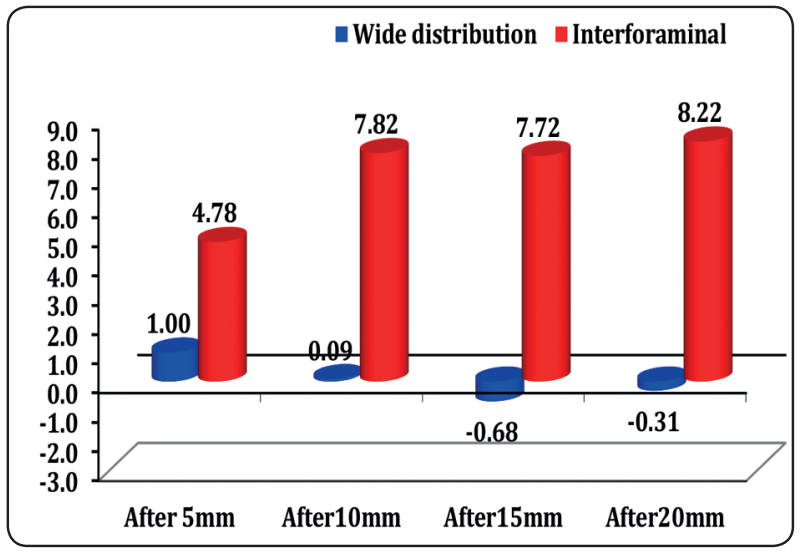

Fig. (5) Bone height changes in wide and interforaminal distribution groups

The concept of a prosthesis assisted only by implants anterior to the mental foramina as described by Branemark and coworkers ${ }^{(22)}$ has several advantages. Placement of implants anterior to the mental foramina allows the engagement of the inferior cortex by tip of the implant or at least guarantee that the implant is placed in the area of greatest density improving the primary stability and increasing the chance of osseointegration. The risk of damage to the mental branch of inferior alveolar nerve is reduced by avoiding more posterior implant placement. ${ }^{(23)}$ 
On the basis of studies on the precision of measurements of mandibular linear dimensions in panoramic radiographs, Larheim et al. ${ }^{(24,25)}$ have indicated that the variability of vertical measurements made from repeated panoramic radiographs is small when patients are properly positioned in the panoramic apparatus. The effect of head position in the panoramic radiograph on vertical measurement ${ }^{(26)}$ showed the possibility of making accurate vertical measurements in both jaws, particularly in the lower jaw. If reference lines and measured points are located in the same vertical plane or in approximately the same plane, variations in vertical measurements in the mandible and the posterior regions of the maxilla fall within a small range.

Reduction of the residual alveolar ridges is progressive in nature with age, the height of the alveolar ridge and basal bone will decrease, resulting in alveolar ridge bone loss as great as $1 \mathrm{~mm}$ per year in complete denture wearers. ${ }^{(27)}$

Another study reported, a negative correlation between age and mandibular bone height in both genders but was found statistically significant in male patients specially $>60$ year. ${ }^{(28)}$

In the 4 interforaminal implant assisted overdentures, majority of stresses are distributed on the posterior basal seat area ${ }^{(29)}$ and bone resorption take place. ${ }^{(12,15,30)}$ The biomechanics of 4 interforaminal implants mandibular overdenture is similar to that of a Kennedy class I removable partial denture. Difference in compressibility between posterior ridge mucosa and osseointegrated implant will cause hinging of denture base around a fulcrum line passing through the two most distal anterior implants. (31) During mastication, the increase in compressive load on the distal over-denture base will increase distal ridge resorption. ${ }^{(30,32,33)}$

Marjolein et al ${ }^{(1)}$ reported that the vertical posterior bone resorption for four implants assisted overdenture was $0.74 \mathrm{~mm}$ in 10 years. Kordatzis et $\boldsymbol{a l}^{(16)}$ reported 0.69 to $1 \mathrm{~mm}$ of posterior residual ridge resorption over five years.
In our study the estimated mandibular ridge height resorption in interforaminal distribution group of mini-implants was $7 \mathrm{~mm}$ or $21 \%$ of residual bone height over six years. The higher value of bone resorption may be caused by use of mini implants instead of standard size implants and aging factor.

In the present study the estimated mandibular ridge height resorption in wide distribution group of mini-implants was $0.03 \mathrm{~mm}$ or $1.7 \%$ of residual bone height over six years.

The posterior implants placement is indicated to favorably change the biomechanical situation. ${ }^{(34)}$ With the posterior implant placement, the denture hinging was significantly reduced, and more of a load was carried with posterior implants. Physiological functional load transmitted to implants will have a positive effect on preservation of the residual alveolar ridge around the implants. ${ }^{(35)}$ The posterior implants would improve the overdenture support, reduce hinging action of denture, and transfer the Kennedy class I implant-and-mucosa supported overdentures to fully implant-supported Kennedy class III design. ${ }^{(34)}$

\section{CONCLUSION}

Posterior mini-implant placement resulted in improved denture support and minimal overdenture displacement. The functional load on posterior mini-implants have a positive effect on preservation of the residual alveolar ridge. Wide mini-implants distribution is an acceptable alternative prosthodontic design to four interforaminal mini-implants distribution when anatomical and economical factors permit.

\section{REFERENCE}

1. Marjolein M, de Jong M, Wright $\mathrm{P}$, Meijer $\mathrm{H}$ and Tymstra N. Posterior mandibular residual ridge resorption in patients with overdentures supported by two or four endosseous implants in a 10-year prospective comparative study. Int J Oral Maxillofac Implants. 2010; 25:1168-74. 
2. Kova I, Elebi A, Knezovi D, Petri N and Bukovi D. Decreasing of Residual Alveolar Ridge Height in Complete Denture Wearers. A Five Year Follow up Study. Coll Antropol. 2010: 34: 1051-1056.

3. Juan F, Azorín M, Segura G, López J and Panadero R. Rehabilitation with implant-supported overdentures in total edentulous patients: A review. J Clin Ex Dent.2013; 5:267-272.

4. Khalifa A, Wada M, Ikebe K and Maeda Y. To what extent residual alveolar ridge can be preserved by implant? A systematic review. Int J Implant Dent. 2016; 2:22-31.

5. Kumari P, Verma M, Sainia V, Gupta A, Gupta R and Gill S. Mini-implants, mega solutions: a case series. J Prosthodont. 2015; 10:12382.

6. Griffitts T, Collins C and Collins P. Mini dental implants: an adjunct for retention, stability, and comfort for the edentulous patient. Oral Surg Oral MedOral Pathol Oral Radiol Endod. 2005; 100:81-4.

7. Shatkin T, Shatkin S, Oppenheimer B and Oppenheimer A. Mini dental implants for long-term fixed and removable prosthetics: a retrospective analysis of 2514 implants placed over a five-year period. Compend Contin Educ Dent. 2007; 28:92-101.

8. Preoteasa E, Imre M and Preoteasa CT. A 3-year follow-up study of overdentures retained by mini-dental implants. Int J Oral Maxillofac Implants. 2014; 29:1170-6.

9. Pongsakorn W, Pimduen R, Chaiy R and Pathawee K. Effects of different numbers of mini-dental implants on alveolar ridge strain distribution under mandibular implantretained overdentures. J prosth research. 2018; 62:35-43.

10. Flanagan D and Mascolo A. The mini dental implant in fixed and removable prosthetics: a review. J Oral Implantol. 2011; 37:123-32.

11. Scepanovic M, Calvo-Guirado JL, Markovic A, DelgardoRuiz R, Todorovic A and Milicic B. A 1-year prospective cohort study on mandibular overdentures retained by mini dental implants. Eur J Oral Implantol. 2012; 5:367-79.

12. Jacobs R, Schotte A, van Steenberghe D, Quirynen M and Naert I. Posterior jaw bone resorption in osseointegrated implant-supported overdentures. Clin Oral Implants Res. 1992; 3:63-70.

13. Blum I and Fraser M. A clinical investigation of the morphological changes in the posterior mandible when implant-retained overdentures are used. Clin Oral Implants Res. 2004; 15:700-8.
14. Raedel M, Lazarek-Scholz K, Marr B, Boening KW and Walter $\mathrm{MH}$. Posterior alveolar ridge resorption in barretained mandibular overdentures: 10-year results of a prospective clinical trial. Clin Oral Implants Res. 2015; 26:1397-401.

15. Wright $P$, Glantz $P$, Randow $K$ and Watson RM. The effects of fixed and removable implant-stabilised prostheses on posterior mandibular residual ridge resorption. Clin Oral Implants Res. 2002; 13:169-74.

16. Kordatzis K, Wright PS and Meijer HJ. Posterior mandibular residual ridge resorption in patients with conventional dentures and implant overdentures. Int J Oral Maxillofac Implants. 2003; 18:447-52.

17. Tiwari1 P, Karambelkar V, Patel J and Sethuraman R. Use of panoramic radiographs for evaluation of maxillary and mandibular residual ridge resorption: invitro study. Evolution of Med and Dent. 2014; 3:60.

18. Sanders D: Mental Foramen Location in Humans, thesis for the MS. degree, University of Texas Dental Branch, Houston, Texas, May, 1972.

19. Arkin H. Handbook of Sampling for Auditing and Accounting, 3rd edition, (McGraw-Hill, 1984) Page 21.

20. Jaykaran C and Tamoghna B. How to Calculate Sample Size for Different Study Designs in Medical Research? Indian J Psychol Med. 2013; 35: 121-126.

21. Stuart C, Michael J. Oral Radiology Principles and interpretation. Chapter 11: Panoramic Imaging, 7TH edition, produced by Mosby Co., St. Louis, 2014.

22. Branemark P,HassonB,Adell R, Breine U, Lindsrtom $\mathrm{J}$ and Hallen O. Ossteointegrated implants in the treatment of edentulous jaw. Experience from a 10 years period. Scand J Plastic Reconstr Sur Suppl. 1977; 16:1-123.

23. Misch C. Contemporary implant dentistry $.3^{\text {th }}$ ed.CV. Mosby Co., St. Louis, Boston, Chicago, London, Philadelphia, Sydney, Toronto, 2008.

24. Larheim TA, Svanaes DB and Johannessen S. Reproducibility of radiographs with the orthopantomograph 5: tooth-length assessment. Oral Surg 1984; 58:736--41.

25. Larheim TA and Svanaes DB. Reproducibility of rotational panoramic radiography: mandibular linear dimensions and angles. Am JOrthod Dentofac Orthop 1986; 90:45-5 I .

26. Xie Q, Soikkonen K, Wolf J, Mattila K, Gong M and Ainamo A. Effect of head positioning in panoramic radiography on vertical measurements: an in-vitro study. Dentomaxillofac Radiol 1996; 25:6 1-6. 
27. Devlin $\mathrm{H}$ and Ferguson MW. Alveolar ridge resorption and mandibular atrophy. A review of the role of local and systemic factors. Br Dent J 1991; 170:101-4.

28. Al AlSheikh H, AlZain S, Warsy A, AlMukaynizi F and AlThomali A. Mandibular residual ridge height in relation to age, gender and duration of edentulism in a Saudi population: A clinical and radiographic study. Saudi Dental Journal 2019; 31:258-264.

29. Topkaya $\mathrm{T}$ and Solmaz M. The effect of implant number and position on the stress behavior of mandibular implant retained overdentures: A three-dimensional finite element analysis. J Biomech. 2015; 48: 2102-2109.

30. Elsyad M, Alokda M, Gebreel A, Hammouda N and Habib A. Effect of two designs of implant-supported overdentures on peri-implant and posterior mandibular bone resorptions: a 5-year prospective radiographic study. Clin Oral Implants Res. 2017; 28: 184-194.

31. Muraki H., Wakabayashi N, Park I and Ohyama T. Finite element contact stress analysis of the RPD abutment tooth and periodontal ligament. J Dent. 2004; 32: 659-665.

32. Ahmad R, Chen J, Abu-Hassan MI, Li Q and Swain MV. Investigation of mucosa induced residual ridge resorption under implant retained overdentures and complete dentures in the mandible. Int J Oral Maxillofac Implants. 2015; 30: $657-666$

33. Tymstra N, Raghoebar G, Vissink A and Meijer H. Maxillary anterior and mandibular posterior residual ridge resorption in patients wearing a mandibular implant retained overdenture. J Oral Rehabil. 2011; 38: 509-516.

34. Ohkubo C, Kurihara D, Shimpo H, Suzuki Y, Kokubo Y and Hosoi T. Effect of implant support on distal extension removable partial dentures: in vitro assessment $\mathrm{J}$ Oral Rehab. 2007;34: 52- 56.

35. Frost H. From Wolff's law to the Uttah Paradigm: Insights about the bone physiology and its clinical application. Anat Rec. 2001; 262: 398- 419. 